\title{
Block Design Subtest (WPPSI-IV)
}

National Cancer Institute

\section{Source}

National Cancer Institute. Block Design Subtest (WPPSI-IV). NCI Thesaurus. Code

C120352.

A subtest of the Wechsler Preschool and Primary Scale of Intelligence, 4th Edition that measures ability to analyze and synthesize abstract visual stimuli. The child views a model and/or a picture in a book and uses one- or two-color blocks to recreate the design. 